responses. The final session was chaired by Anthony Clare. Terry Sprately, Canterbury, described the challenges and conflicts of running a multidisciplinary team and this was complemented by Anthony Thorley's view of the application of psychodynamic psychotherapy in the treatment of substance problems. A lively discussion on the role of general practitioners in the management of problem drug users rounded off an intensive week of lectures and small group discussions.

\title{
Behavioural family therapy: cost-effective schizophrenia care $^{*}$
}

\section{DAVID G. WALBRIDGE, Senior Registrar in Psychiatry, Littlemore Hospital, Littlemore, Oxford OX4 4XN}

The recent shift in emphasis from treatment in hospital to management in the community has led to patients with schizophrenia being cared for on a dayto-day basis not by trained staff but by relatives acting as non-professional carers. It has become evident that the outcome of this policy depends very much on the level and quality of support given to these carers. 'Community care' can be, and often is, no more than a burden for families to carry, but with effective family intervention, relapse of schizophrenic illness can be minimised while quality of life and level of functioning for both patient and family can be maximised.

Essentially, the aim of family intervention is to consider the family not as a problem which requires treatment but as a resource which, with training, can be utilised as the primary care team for the patient. Senior Clinical Psychologist Joanne Smith described a project in Worcester which has successfully involved relatives in the monitoring and early prediction of schizophrenic relapse. With most patients exhibiting one to two weeks of non-specific symptoms such as anxiety, mild depression and disinhibited behaviour immediately prior to relapse, family members are ideally placed to detect and report such symptoms, thus reducing the chance of hospital admission becoming necessary.

In terms of family therapy, the commonest basis is behavioural. A typical programme begins with the exchange of information by means of family sessions and written material. An assessment is made of the problems encountered by relatives and the ways in which they have been trying to overcome them; commonly, problems seem to stem from difficulties in coping with negative symptoms such as apathy, poor self-care and a lack of motivation and initiative. Clinical details such as the diagnosis and proposed plan of management are discussed, along with aspects of aetiology and the likely course of the illness. Continuing sessions are designed to reduce the level of expressed emotion and to increase the patient's capacity for independence by adopting a positive, goal-directed, problem-solving approach.

Dr Ian Falloon reported that results from his project in Buckingham suggest that the entire service, including the management of acute schizophrenic episodes, can be run using an intensive family-based programme. However, the trend elsewhere will probably be for acute episodes to continue to be treated in hospital and the application of family behavioural therapy will be as a part of the overall management plan. As well as improving the quality of the service, the decrease in relapse rate and consequent hospital admission should eventually reduce the total cost of managing schizophrenia, perhaps by as much as $30 \%$ according to Ian Falloon's findings.

Costs in the first few years will however be higher for two main reasons. Firstly, there is the requirement for additional staff, facilities and training. Secondly, in the early years of establishing the service, the majority of the clientele will be the preexisting pool of patients with schizophrenia and their families. In order to bring about the overall reduction in relapse rate necessary to achieve costeffectiveness, it is essential that a sufficient proportion of the families in need are contacted and engaged. This can best be achieved by offering a service which is perceived by families as being appropriate and helpful and by promoting a public awareness that family behavioural therapy is an integral component of the management of schizophrenia, so that families will actively seek it as a matter of right in the same way in which they would seek medical treatment.

*National Schizophrenia Fellowship seminar held in Oxford, 10 October 1989. 